\title{
Regime shifts of hydrometeorological factors in the Jiaozhou Bay and their potential ecological impacts
}

ARTICLE in CHINESE JOURNAL OF GEOCHEMISTRY • DECEMBER 2013

DOI: 10.1007/s11631-013-0653-z

DOWNLOADS

40
VIEWS

72

4 AUTHORS, INCLUDING:

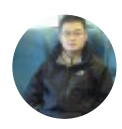

Zhe Liu

National Natural Science Foundation of Chi..

22 PUBLICATIONS 188 CITATIONS

SEE PROFILE

Dongyan Liu

Chinese Academy of Sciences

135 PUBLICATIONS 1,158 CITATIONS

SEE PROFILE
Hao Wei

Tianjin University

58 PUBLICATIONS 542 CITATIONS

SEE PROFILE 


\title{
Regime shifts of hydrometeorological factors in the Jiaozhou Bay and their potential ecological impacts
}

\author{
LIU Zhe ${ }^{1,2^{*}}$, ZHANG Jing ${ }^{2}$, WEI Hao ${ }^{3}$, and LIU Dongyan ${ }^{4}$ \\ ${ }^{1}$ Key Laboratory of Marine Environment and Ecology (Ocean University of China), Ministry of Education, Qingdao 266100, China \\ ${ }^{2}$ State Key Laboratory of Estuarine and Coastal Research, East China Normal University, Shanghai 200062, China \\ ${ }^{3}$ College of Marine Science and Engineering, Tianjin University of Science and Technology, Tianjin 300457, China \\ ${ }^{4}$ Yantai Institute of Coastal Zone Research, Chinese Academy of Sciences, Yantai 264003, China \\ *Corresponding author, E-mail: liuzhehd@263.net
}

Received October 10, 2012; accepted November 10, 2012

C) Science Press and Institute of Geochemistry, CAS and Springer-Verlag Berlin Heidelberg 2013

\begin{abstract}
The wavelet transform was applied to studying the regime shifts of hydrometeorological factors (i.e., precipitation, air temperature, sea surface temperature and sea surface salinity) during the period of 1961-2000 in the Jiaozhou Bay (JZB). The results indicated clearly that these factors show variability of multiple timescales, with interannual and decadal periods. The local abrupt changes such as the 1978-1979 and 1988-1989 shifts feature the physical environment variation, which is consistent with the Southern Oscillation and Arctic Oscillation in the northern hemisphere. In regard to the JZB ecosystem, the benthic diatom cell abundance (BEN) showed a decrease shift in 1978-1979, which is closely related to the precipitation abrupt decrease, while the shellfish mortality disaster in the JZB greatly released the predating pressure of diatom growth, possibly resulting in BEN increase shift in 1995.
\end{abstract}

Key words regime shift; multiple timescale; ecological impact; Jiaozhou Bay

\section{Introduction}

The coastal physical environment on a local spatial scale features a significant variation in long-term evolution trend. The physical forces, including wind speed and thermohaline structure with interannual and decadal variations, affect the circulation pattern dramatically, resulting in ecosystem instabilities. For instance, the sea temperature anomalies alter the patterns of net surface-heat fluxes, turbulent mixing, and horizontal transport in southern California Current, which is the most important mechanism for the observed plankton decline, and subsequent ecosystem changes (Mcgowan et al., 2003).

Regime shift is defined as a relatively brief time period when key state variables of a system are in transition between different quasi-stable states (Mantua, 2004). Since it always represents rapid reorganization of the ecosystem under study, it is usually re- garded as one of the foremost important phenomena among the kinds of temporal evolutions in a coastal area. The occurrence of a major shift is helpful for the researchers and planners in their strategy-setting for more comprehensive analysis of complex environment variation and in sound decision-making processes (Chu Paoshin and Zhao Xin, 2003). During the past several decades, more and more evidence has been developed to support that regime shifts occurred in the early 1920s, the mid 1940s, the 1970s and the late 1980s (Graham, 1994; Minobe, 1997; Hare and Mantua, 2000; Denman and Pena, 2002).

It has been realized by many studies that long-term change may inherently feature multiple timescale oscillation (Chylek et al., 2009; Miettinen et al., 2012). These periodic oscillations were proved to be non-stable in the time-frequency domain (Torrence and Compo, 1998). The ocean-atmosphere system has variability on three distinct timescales: interannual, 
decadal and interdecadal scales (Mann and Park, 1996). Therefore, it is reasonable to study regime shift on multiple timescales. In other words, regime shift on different time scales might not be the same. However, it is relatively seldom reported how regime shift depends on the timescale selected.

In addition, the physical environment variation on a local scale may be strongly affected by climate change on a basin-wide or even global scale through teleconnection. For instance, if there are decadal oscillations intrinsic to the tropical Pacific, they would be likely to teleconnect to the mid-latitudes and produce decadal variations there which resemble the interannual patterns associated with El Nino (e.g. Zhang Yuan et al., 1997). In regard to the coastal area, most studies on local environmental variability focus on intensive human activities (e.g. land reclamation, warm water discharge, and eutrophication), but fail to give priority to climatic regime shift on a global scale.

In this study, the multiple timescales regime shift, as well as periodic oscillation of hydrometeorological factors in the Jiaozhou Bay, a small coastal bay heavily influenced by human activities, was analyzed by wavelet transform. Special attention was paid to the similarities of local and global climate changes and relations of regime shifts between physical and biological factors.

\section{Study area}

The Jiaozhou Bay (JZB), with a surface area of about $400 \mathrm{~km}^{2}$, is located along the western coast of the Yellow Sea (YS) $\left(35^{\circ} 58^{\prime}-36^{\circ} 18^{\prime} \mathrm{N}, 120^{\circ} 04^{\prime}-\right.$ $120^{\circ} 23^{\prime} \mathrm{E}$ ), and it is a partly enclosed waterbody with a channel that connect the bay with YS (Fig. 1). The JZB features high primary production and supports greatly the economic development in the surrounding areas. For instance, the marine culture area in the JZB is about $150 \mathrm{~km}^{2}$ (Guo Yonglu et al., 2005). The annual production of scallops was about $8.1 \times 10^{-4} \mathrm{t}$ in 1995 (Lu Jiwu et al., 2001). In the mean time, like other eutrophicated coastal areas in China (e.g. Changjiang Estuary), the marine environment around the JZB suffers from strong human activities, such as eutrophication and biodiversity reduction. It is widely emphasized that human impact (such as marine aquaculture) plays a foremost role in driving these changes in the JZB (Liu Sumei et al., 2010). However, whether the local climate variability around the JZB features abrupt changes related to global change and whether these abrupt changes can dramatically affect the marine ecosystem, even resulting in regime shift, are not clear.

\section{Data and methods}

\subsection{Data collected}

Listed in Table 1 are the data sources. The collected historical hydrographical, meteorological and biological data for the period from 1961-2000 in the Jiaozhou Bay were analyzed, including: (1) sea surface temperature (SST), (2) sea surface salinity (SSS), (3) air temperature (AT), (4) precipitation (PR), and (5) benthic diatom cell abundance (BEN). The first four data, i.e., hydrographical and meteorological data, are recorded, respectively, at Xiaomaidao (XM) and

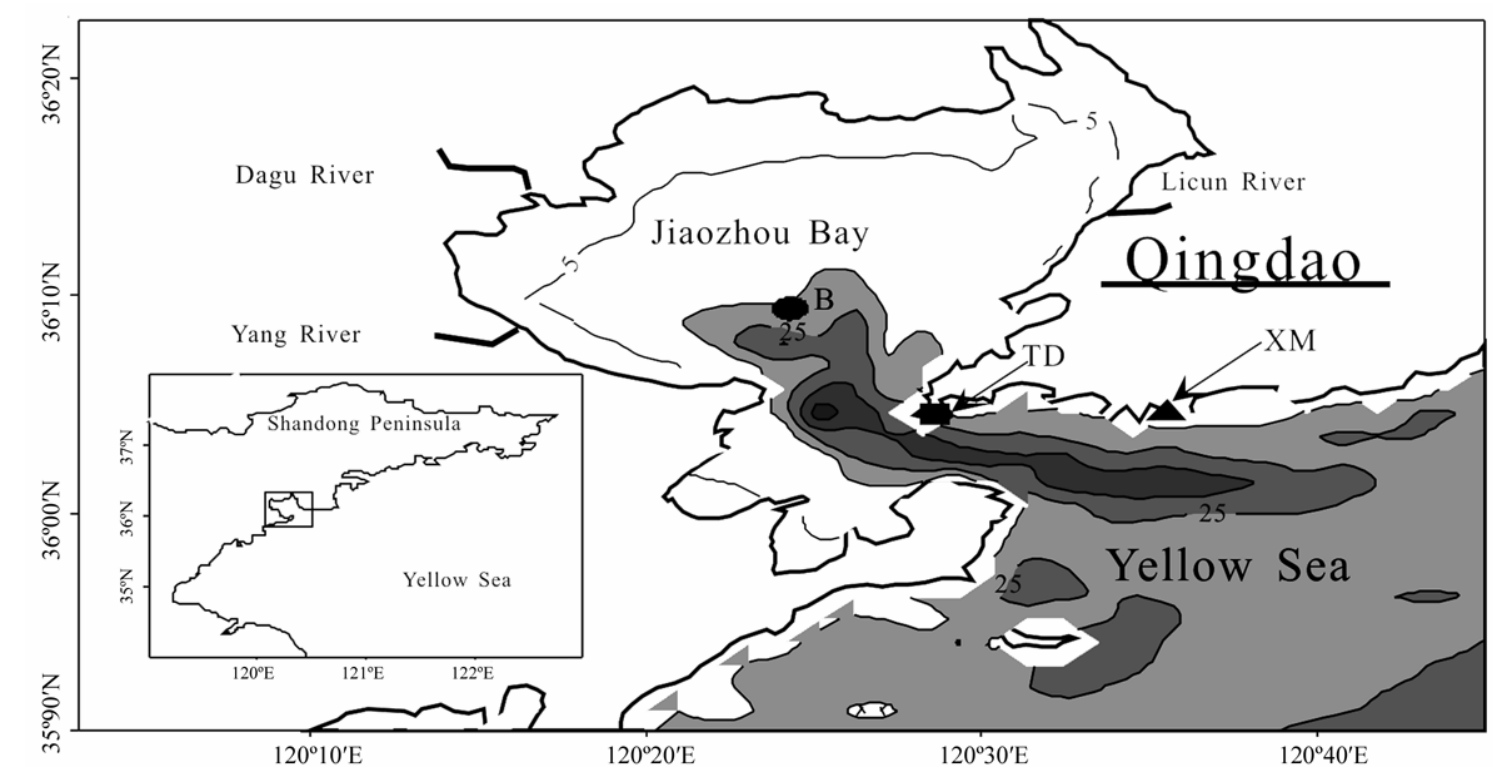

Fig. 1. Topography $(\mathrm{m})$ of the JZB with the location map inserted on the lower left, and sampling stations around the JZB. TD and XM are, respectively, the stations for measuring meteorological and hydrographical parameters. The benthic diatom cell abundance from the sediment record is given in $\mathrm{B}$. 
Table 1 The brief description of the observation data used in this study

\begin{tabular}{cccccc}
\hline No. & Abbreviation & Full name & Period & Interval & Source \\
\hline 1 & SST & Sea surface temperature & $1961-2000$ & 1 month & XM station \\
2 & AT & Air temperature & $1961-2000$ & 1 month & TD station \\
3 & PR & Precipitation & $1961-2000$ & 1 month & TD station \\
4 & SSS & Sea surface salinity & $1961-2000$ & 1 month & XM station \\
5 & SOI & Southern Oscillation Index & $1961-2000$ & 1 month & NOAA* \\
6 & AO & Arctic Oscillation & $1961-2000$ & 1 month & NOAA* \\
7 & YS SST & Yellow Sea surface temperature & $1961-2000$ & 1 month & NCEP \\
8 & BEN & Benthic diatom cell abundance & $1961-2000$ & 1 year & Liu Dongyan, 2004 \\
\hline
\end{tabular}

Note: * http://www.cdc.noaa.gov/Pressure/Timeseries/

Tuandao (TD) (Fig. 1). The BEN was taken from the doctoral dissertation by Liu Dongyan (2004). The original sediment data include those collected in the period of 1889-2001 with a total of 100 records; by the interpolation method, the subsets were taken in the time period from 1961 to 2000 , the same period as the physical data. The three stations are quite nearby, with the maximum distance of $<25 \mathrm{~km}$. The physical data in this study are of continuity, high sample resolution, with longer lifespan, compared with the data used in previous studies on China's coastal environmental variability (Lin Chuanlan et al., 2001; Fang Guohong et al., 2002) and the data derived from network stations of the State Oceanic Administration of China (Lin Chuanlan et al., 2005).

To analyze the local response to the environmental change on the Pacific-scale and marginal sea-basin scale, the monthly data-South Oscillation Index (SOI), SST in the Yellow Sea (YS-SST), and Arctic Oscillation (AO) are employed. SOI can be used to describe the ENSO events. YS-SST, with the resolution of $2^{\circ}$ latitude $\times 2^{\circ}$ longitude, was retrieved from the global gridded optimally interpolated SST dataset of Reynolds and Smith (1994). In this study, the series of YS-SST is the spatial mean of the total 9 water grids in YS. In the large-scale mode of atmospheric variations, $\mathrm{AO}$ is derived as the leading principal of global winter sea level pressure, which is centered on the Arctic and extends southward into the North Atlantic and Pacific (Thompson and Wallace, 1998). According to Thompson and Wallace (1998), $\mathrm{AO}$ and ENSO play an equal and profound role in the variability of the north hemisphere climate system.

\subsection{Wavelet transform}

Wavelet, a multi-resolution analytical tool commonly used in geophysics, can be used to determine time series containing non-stationary power by decomposing the time series into time-frequency space (Daubechies, 1992). In this study, two mother wave- lets are employed, Morlet and Haar. By Morlet wavelet transform, we revealed whether the time series features multiple-timescale oscillation, and the power spectrum is obtained, while Haar wavelet is used to detect regime shift. Since Morlet has been widely applied in geoscience studies (e.g. Miettinen et al., 2012), only the theory and algorithm of Haar wavelet transform is shown.

The earmarks of "regime shifts" are the abrupt transition from one stable state to another. Haar wavelet basis function is the best candidate for describing regime change because of its step-like character (Eq. 1). Haar wavelet basis function is

$$
\Psi\left(\frac{t-\tau}{s}\right)=-1 \quad \begin{array}{cc}
1 & t \in[\tau-s / 2, \tau) \\
0 & t \in[\tau, \tau+s / 2] \\
& t \in-s / 2, \tau+s / 2]
\end{array}
$$

where, $t, s$ and $\tau$ are the time, scale and time moving factor, respectively. Given a time series $[x(t)]$ and a certain scale $(s)$, the wavelet coefficient series, $W(t, s)$, can be obtained by the convolution below

$$
W(t, s)=\frac{1}{\sqrt{s}} \int_{T} x(\tau) \Psi^{\prime}\left(\frac{t-\tau}{s}\right) d \tau
$$

where, $t$ is the time range, and $\Psi^{\prime}$ is the conjugate of $\Psi$. Clearly, shift occurs when $t=\tau$. With the moving of $t$, the step-like variation is obtained; and as the scale is flexed, the temporal variation for regime shifts on multiple timescales can be revealed (Eq. 2).

The details of the significance test for real wavelet power (including Haar) can be found in Torrence and Compo (1998). Here, only main procedures and formulae are briefly introduced. Red noise is supposed to be the time series background in geoscience. Its power spectrum after normalizing is

$$
P_{s}=\frac{1-\alpha^{2}}{1+\alpha^{2}-2 \alpha \cos (2 \pi / s)}
$$


where $\alpha$ is the autocorrelation coefficient with lag time of one sampling interval, and $s$ is the examined timescale with unit in sampling interval. $W^{2}(t, s)$ is distributed as $\sigma^{2} P_{\mathrm{s}} x_{1}^{2}$, where $\sigma^{2}$ is the variance of $[x(t)]$, and $x_{1}^{2}$ means chi-square distribution with one degree of freedom. After choosing a specified confidence level ( $p=0.05$, in this study) for $x_{1}^{2}$, if $W^{2}(t, s)$ $\geq \sigma^{2} P_{s} x_{1}^{2}, t$ can be regarded as the time when the regime shift occurs at $0.5 s$-period. Since Haar uses a downward step function, the positive (negative) wavelet coefficient is associated with a decreasing (increasing) trend on a given timescale.

\section{Results and discussion}

\subsection{Interannual and decadal variabilities}

The monthly means of SST, AT, PR and SSS are, respectively, 13.7 and $12.6^{\circ} \mathrm{C}, 56 \mathrm{~mm}$, and 31.17 . All the parameters feature an unimodal temporal pattern (Fig. 2a, c, e, g). SST and AT reach their maxima in August and minima in February and January, respectively. A remarkable monthly difference was found in $\mathrm{PR}$ distribution. For instance, the precipitation in $\mathrm{Au}-$ gust contributes over $21.7 \%$ to the annual total, but less than $1.5 \%$ in January. SSS is high in winter and spring with the peak value of 31.49 in March and low in summer and autumn.

There are remarkable interannual variations in hydrographical and meteorological data (Fig. 2b, d, f, h). According to the linear regression results, the trends of the annual means SST, AT, PR and SSS are, respectively, 0.025 and $0.028^{\circ} \mathrm{C} \cdot \mathrm{a}^{-1},-5.06 \mathrm{~mm} \cdot \mathrm{a}^{-1}$, and $0.028 \mathrm{a}^{-1}$. During 1961-2000, these linear trends for the annual mean parameters resulted in an increase of $1.00^{\circ} \mathrm{C}$ for SST, $1.12^{\circ} \mathrm{C}$ for AT and $1.12^{\circ} \mathrm{C}$ for SSS, and a decrease of $202 \mathrm{~mm}$ for PR, respectively. The interannual trends are of significant difference during each decade. SST and AT were characterized by reduction in the 1960s, while increasing thereafter. SSS showed a positive trend in the 1960s and 1970s and a negative one in the 1980s and 1990s (Table 2). The temporal distribution of PR has an opposite phase to that of SSS.

A-SST, A-AT, A-PR, and A-SSS (the normalized monthly anomalies for the SST, AT, PR, and SSS) are obtained by subtracting the monthly means from original data and then dividing them by their standard deviations. The power spectra of the anomalies for the hydrological and meteorological regimes have peaks mainly on interannual or decadal timescales (Fig. 3). On decadal time scales, significant peak values are seen to occur at $\sim 13$-year, with this variability playing the most important role for A-AT and A-SSS, while energy component of other scales cannot be compared with that of decadal timescale. A-SST decadal fluctuation is not as strong as that of A-PR. In regard to the interannual timescales, all the parameters feature a $\sim 5$-year wave component. A-SST and A-SSS are also considerably affected by the $\sim 2.5$-year oscillation; however this energy component is clearly lower than that of $\sim 5$-year. $\sim 8$-year period variability is predominant for A-AT, while this component is not significant for A-SST.

Table 2 The linear trends of the JZB physical parameters in each decade and the entire 40-years period

\begin{tabular}{ccccc}
\hline Period & $\begin{array}{c}\mathrm{SST} \\
\left({ }^{\circ} \mathrm{C} \cdot \mathrm{a}^{-1}\right)\end{array}$ & $\begin{array}{c}\mathrm{AT} \\
\left({ }^{\circ} \mathrm{C} \cdot \mathrm{a}^{-1}\right)\end{array}$ & $\begin{array}{c}\mathrm{PR} \\
\left(\mathrm{mm} \cdot \mathrm{a}^{-1}\right)\end{array}$ & $\begin{array}{c}\mathrm{SSS} \\
\left(\mathrm{a}^{-1}\right)\end{array}$ \\
\hline $1961-1970$ & -0.119 & -0.109 & -30.93 & 0.148 \\
$1971-1980$ & 0.052 & 0.037 & -20.44 & 0.072 \\
$1981-1990$ & 0.027 & 0.037 & 35.16 & -0.081 \\
$1991-2000$ & 0.135 & 0.077 & 26.55 & -0.031 \\
$1961-2000$ & 0.025 & 0.028 & -5.06 & 0.028 \\
\hline
\end{tabular}

A continuous wavelet analysis, with Morlet transform, was performed to investigate the timefrequency variance for each parameter. The results are shown in Fig. 4 with the year on the abscissa and the return period (years) on the denary-logarithm scaled ordinate. Variability in time-frequency pattern of A-SST is apparently identical to that of A-AT, which is also consistent with correlation and spectrum analysis. Energy in low frequencies (10-20 years) was stable throughout the 40 years, while that in the mid-range (5-8 years) became steady after 1970 . The higher frequencies (2-5 years) exhibited a notable period-transition during 1972-1980. For instance, the most important period for interannual timescales involved 2-2.5 years in 1972-1975, and 3-4 years thereafter. The patterns of time-frequency variability in A-SST and A-AT also had a few differences particularly after 1990 when high frequencies (1-2 years) appeared to be stronger in A-SST than A-AT. Similar to A-SST and A-AT, the time-frequency patterns of A-SSS and A-PR exhibited a close relationship featuring identical intensity, but an opposite phase (Fig. $4 \mathrm{c}$ and $\mathrm{d}$ ). The low-frequencies band was much stronger in the 1970s and 1980s than that in the last two decades. The mid-range was steady in the 1970s, while the energy in this band was obviously higher in A-PR than in A-SST. After 1985, the mid-range energy maxima in A-PR shifted to 5-6-year periods. In the meantime, both decadal and interannual cycles were remarkably weakened. 


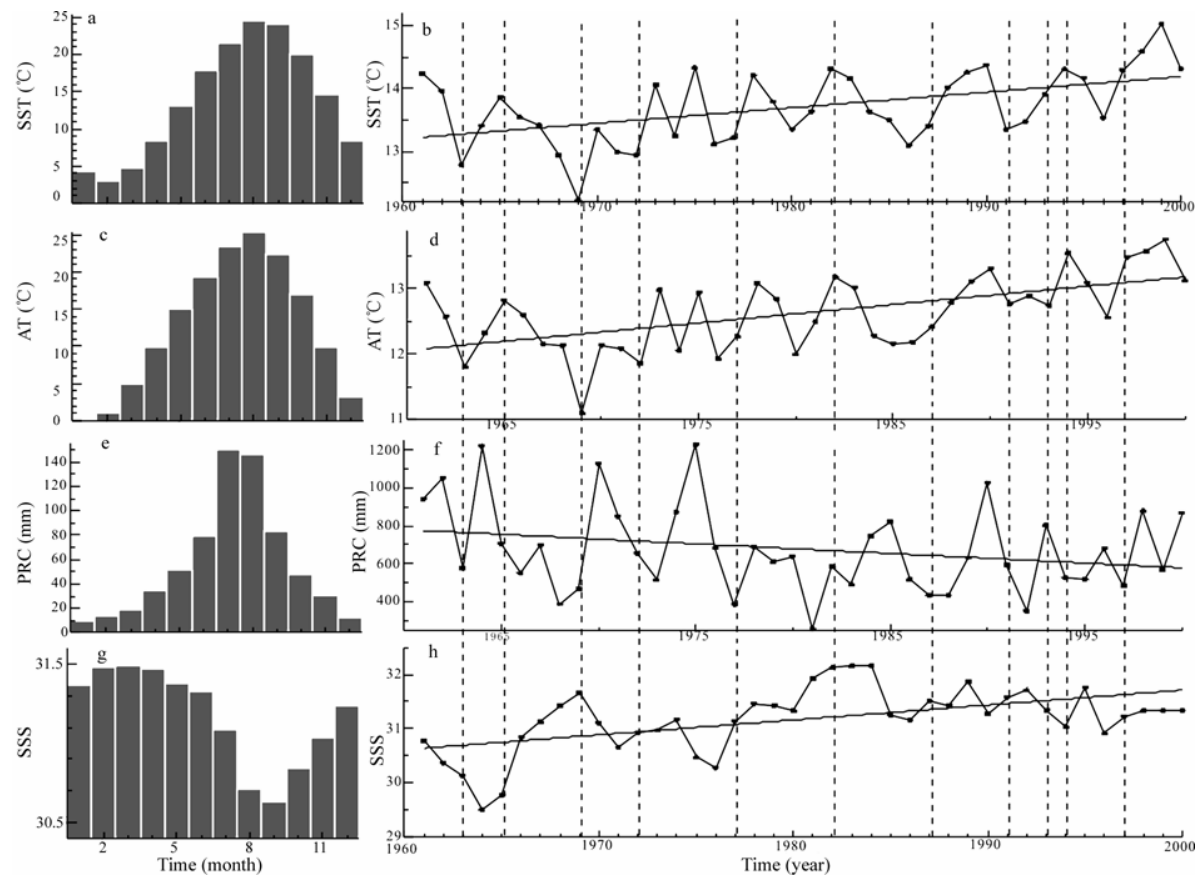

Fig. 2. The seasonal (left) and interannual (right) variations of physical parameters in the JZB. The bold lines in the interannual variation curves show their linear regression result. The dashed lines indicate the ENSO events.
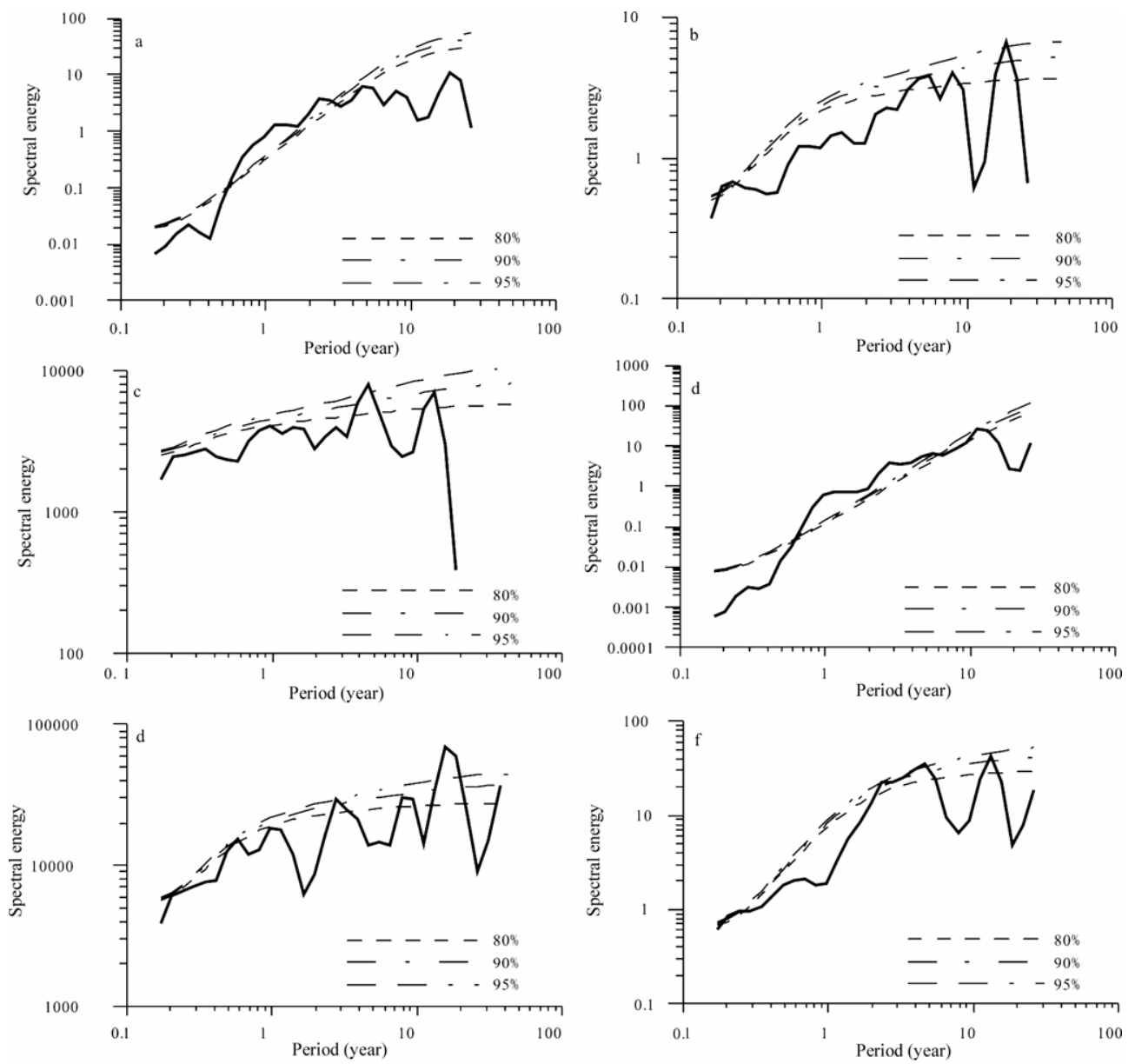

Fig. 3. Power spectrum analysis of the physical parameters on monthly anomalies [A-AT (a), A-SST (b), A-PR (c) and A-SSS (d)] as well as AO (e) and SOI (f) 

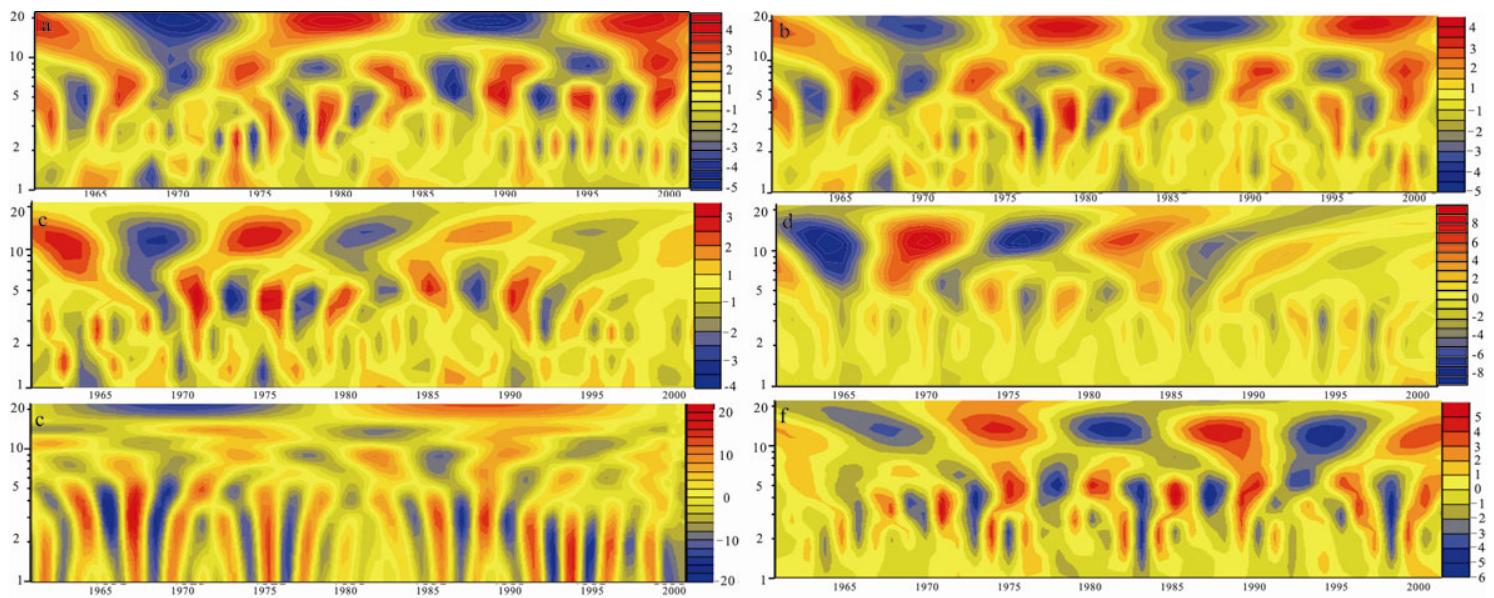

Fig. 4. Morlet wavelet transform coefficients of the physical parameters monthly anomalies [A-AT (a), A-SST (b), A-PR (c) and A-SSS (d)] as well as AO (e) and SOI (f)].

\subsection{Multiple timescale regime shifts}

According to Haar wavelet analysis, the 19761978 regime shift proves itself to be significant for the temporal change in the first two primary components (EOF1 and EOF2 in Table 3) for all the physical parameters throughout the examined scales, while the 1988-1989 shift in the second primary component is only on a short scale (2-year period). This suggests that the small spatial scale region, like JZB, might be affected significantly by global-scale climate events, $\mathrm{AO}$ and ENSO, and the first world-wide global change (1976-1977 shift) is more important for the JZB system. In regard to decadal variation for A-SST, the shift in 1977 made SST increase by $0.54^{\circ} \mathrm{C}$. Although A-SST is highly correlated to A-AT, the 1977 shift is not significant on such a scale, and neither is YS A-SST. This suggests that the origination of decadal shift for A-SST is not due to the linear process of heat flux at the interface between bay water and air, nor water exchange between JZB and YS. Therefore, the nonlinear process might be the only potential factor corresponding to such phenomenon. Another interesting phenomenon is that A-SST continuously increased after 1988 and so did A-AT on an interannual scale. However, a lot of literature reported that the basin- scale shift in 1988-1989 brought the global climate system to a colder regime, although this regime was still warmer than that before 1976-1977. This phenomenon is confirmed in the North and East Pacific (Hare and Mantua, 2000). The A-AT and YS A-SST also showed an increasing trend around 1989, which results in A-SST increase. Nevertheless, what drives AT over JZB and SST in YS varies at opposite phase with global change should be examined on a larger spatial scale focusing on the western part of the
Pacific. SSS change could be explained by the combination of the river discharge, precipitation, evaporation, and intrusion of YS with high salinity. However, the recent 40 -years salinity data on YS are rare. Precipitation can provide freshwater input for the JZB, since the surrounding seasonal rivers discharge is dependent on precipitation. Although the decrease of evaporation in 1977-1978 on a 5-year scale might increase salinity in the JZB, A-SSS shows an evident increase owing to precipitation decrease itself and the induced river discharge decrease. The shift on 20-year scale for A-PR plays a dominant role for A-SSS shift in 1980, with a lag time of $<1$ year.

The A-PR shift in the early 1970s may be related to the variability of the Siberia High and Aleutian Low (Savelieva et al., 2000), the alternation of its position and intensity over the North Asia induced a different pattern of atmospheric circulation, and further precipitation. The 1980 shift for A-SSS was consistent with that of the Bohai (Lin Chuanlan et al., 2001). Other shifts such as those in 1985 for A-SSS as well as A-AT may be related to the local scale climate change.

The findings in this study accord with other research work in central and eastern North Pacific (Table 4 and Fig. 5). Analyzing the 32 data series in Hare and Mantua (2000) showed that a total of 25 series feature significant abrupt changes $(p<0.1)$. Most of the abrupt changes happened at about 1977 and 1988. Fishery resources' dramatic changes appear along with climate variations (e.g. central Alaska coho catch). Combined with the results of this study, such a conclusion can be drawn that the abrupt changes due to global change as well as their ecology impacts are significant not only in the central and eastern parts of the North Pacific, but also in the marginal seas' coastal regions of the West Pacific. 
Table 3 The abrupt changes of the monthly physical parameters anomalies, their primary components, Yellow Sea SST anomaly, SOI and AO

\begin{tabular}{|c|c|c|c|}
\hline Name & $\begin{array}{l}\text { Scale } \\
\text { (a) }\end{array}$ & Time for abrupt change & Type \\
\hline \multirow{4}{*}{ A-SST } & \multirow{2}{*}{10} & August, 1966 & $\downarrow$ \\
\hline & & January, 1973 & $\uparrow$ \\
\hline & \multirow{2}{*}{20} & December, 1972 & $\uparrow *$ \\
\hline & & August, 1977 & $\uparrow *$ \\
\hline \multirow{2}{*}{ A-SSS } & 10 & June, 1966 & $\uparrow *$ \\
\hline & 20 & May, 1980 & $\uparrow$ \\
\hline \multirow{4}{*}{ A-AT } & \multirow{3}{*}{10} & November, 1967 & $\downarrow *$ \\
\hline & & Novemver, 1972 & $\uparrow *$ \\
\hline & & July, 1988 & $\uparrow^{*}$ \\
\hline & 20 & Decmeber,1989 & $\uparrow *$ \\
\hline \multirow{4}{*}{ A-PR } & \multirow{3}{*}{10} & April, 1966 & $\downarrow *$ \\
\hline & & September, 1970 & $\uparrow *$ \\
\hline & & July, 1979 & $\downarrow *$ \\
\hline & 20 & August, 1979 & $\downarrow *$ \\
\hline \multirow{3}{*}{ EOF 1} & \multirow{2}{*}{10} & July, 1977 & $\uparrow^{*}$ \\
\hline & & April, 1984 & $\downarrow$ \\
\hline & 20 & August, 1977 & $\uparrow *$ \\
\hline \multirow{5}{*}{ EOF2 } & \multirow{4}{*}{10 -year } & February, 1966 & $\downarrow *$ \\
\hline & & May, 1970 & $\uparrow$ \\
\hline & & July, 1977 & $\downarrow^{*}$ \\
\hline & & April, 1984 & $\uparrow$ \\
\hline & 20 & July, 1979 & $\downarrow *$ \\
\hline \multirow{6}{*}{ YS-SSTA } & \multirow{4}{*}{10} & February, 1966 & $\downarrow$ \\
\hline & & January, 1972 & $\uparrow *$ \\
\hline & & June, 1977 & $\downarrow^{*}$ \\
\hline & & June, 1989 & $\uparrow^{*}$ \\
\hline & \multirow{2}{*}{20} & May, 1981 & $\downarrow *$ \\
\hline & & December, 1990 & $\uparrow *$ \\
\hline \multirow{6}{*}{ SOI } & \multirow{4}{*}{10} & July, 1971 & $\uparrow^{*}$ \\
\hline & & July, 1976 & $\downarrow^{*}$ \\
\hline & & May, 1988 & $\uparrow *$ \\
\hline & & May, 1993 & $\downarrow *$ \\
\hline & \multirow{2}{*}{ 20-year } & July, 1976 & $\downarrow *$ \\
\hline & & March, 1986 & $\uparrow^{*}$ \\
\hline \multirow{3}{*}{$\mathrm{AO}$} & \multirow{2}{*}{10} & June, 1976 & $\uparrow^{*}$ \\
\hline & & March, 1988 & $\downarrow$ \\
\hline & 20 & July, 1976 & $\uparrow^{*}$ \\
\hline
\end{tabular}

Note: ' $\downarrow$ ' and ' $\uparrow$ ' stand for decrease shift and increase shift, respectively. The shift is confirmed if its significance level is over $90 \%$ ('*) for $95 \%$ ).
Table 4. The abrupt changes of the 32 selected series with the lifespan of 1965-1997, retrieved from Hare and Mantua (2000), in the central and eastern of the North Pacific Ocean

\begin{tabular}{|c|c|c|c|}
\hline No. & $\begin{array}{l}\text { Abbrevia- } \\
\text { tion }\end{array}$ & Full name & $\begin{array}{c}\text { Shift } \\
\text { period }\end{array}$ \\
\hline 1 & NPATMOS & $\begin{array}{l}\text { North Pacific Atmospheric Pres- } \\
\text { sure Index }\end{array}$ & $\begin{array}{c}1977\left(\uparrow^{*}\right) \\
1988(\downarrow)\end{array}$ \\
\hline 2 & PDOWIN & $\begin{array}{l}\text { Pacific Decadal Oscilla- } \\
\text { tion-winter index }\end{array}$ & $\begin{array}{l}1977\left(\uparrow^{*}\right) \\
1989\left(\downarrow^{*}\right)\end{array}$ \\
\hline 3 & PDOSUM & $\begin{array}{l}\text { Pacific Decadal Oscilla- } \\
\text { tion-summer index }\end{array}$ & l \\
\hline 4 & $\begin{array}{c}\text { NINO34WI } \\
\mathrm{N}\end{array}$ & ENSO 3.4-winter index & 1979(个) \\
\hline 5 & $\begin{array}{l}\text { NINO34SU } \\
\mathrm{M}\end{array}$ & ENSO 3.4-summer index & $1970(\downarrow)$ \\
\hline 6 & KSAT & King Salmon, AK air temperature & $1977\left(\uparrow^{*}\right)$ \\
\hline 7 & CBAT & Cold Bay, AK air temperature & $1988(\downarrow)$ \\
\hline 8 & PISST & $\begin{array}{l}\text { Pribilof Islands sea surface tem- } \\
\text { perature }\end{array}$ & $1989\left(\downarrow^{*}\right)$ \\
\hline 9 & EBSPOLL & $\begin{array}{l}\text { Eastern Bering Sea walleye Pol- } \\
\text { lock recruitment }\end{array}$ & $1983\left(\downarrow^{*}\right)$ \\
\hline 10 & CAK_CO & Central Alaska coho catch & $1977\left(\uparrow^{*}\right)$ \\
\hline 11 & $C A K_{-} P I$ & Central Alaska pink catch & $1976\left(\uparrow^{*}\right)$ \\
\hline 12 & $S A K_{-} C O$ & Southeast Alaska coho catch & I \\
\hline 13 & $S A K_{-} P I$ & Southeast Alaska pink catch & l \\
\hline 14 & SKEESTR & Skeena River stream flow & $\begin{array}{c}1977\left(\downarrow^{*}\right) \\
1988(\uparrow)\end{array}$ \\
\hline 15 & KISST & $\begin{array}{l}\text { Kains Island sea surface tem- } \\
\text { perature }\end{array}$ & $\begin{array}{c}1971(\downarrow) \\
1977\left(\uparrow^{*}\right)\end{array}$ \\
\hline 16 & U51N131W & Upwelling at $51 \mathrm{~N}, 131 \mathrm{~W}$ & $\begin{array}{c}1980\left(\downarrow^{*}\right) \\
1988(\uparrow)\end{array}$ \\
\hline 17 & NDR & Northern diversion rate & $\begin{array}{l}1978(\uparrow) \\
1991(\uparrow)\end{array}$ \\
\hline 18 & $B C \_P I$ & $\begin{array}{l}\text { British Columbia pink salmon } \\
\text { catch }\end{array}$ & $1992\left(\downarrow^{*}\right)$ \\
\hline 19 & FORAT & Forks, WA air temperature & $1974\left(\uparrow^{*}\right)$ \\
\hline 20 & NEWAT & Newport, OR air temperature & l \\
\hline 21 & EURAT & Eureka, CA air temperature & $1980\left(\uparrow^{*}\right)$ \\
\hline 22 & COLSTR & Columbia River stream flow & l \\
\hline 23 & 8RIVSTR & 8 Rivers index & $\begin{array}{l}1980\left(\uparrow^{*}\right) \\
1987\left(\downarrow^{*}\right)\end{array}$ \\
\hline 24 & SCRSST & $\begin{array}{l}\text { Scripps' pier sea surface tem- } \\
\text { perature }\end{array}$ & $1977\left(\uparrow^{*}\right)$ \\
\hline 25 & $\mathrm{U} 48 \mathrm{~N} 125 \mathrm{~W}$ & Upwelling at $48 \mathrm{~N}, 125 \mathrm{~W}$ & $1983(\downarrow)$ \\
\hline 26 & $\mathrm{U} 42 \mathrm{~N} 125 \mathrm{~W}$ & Upwelling at $42 \mathrm{~N}, 125 \mathrm{~W}$ & l \\
\hline 27 & U36N122W & Upwelling at $36 \mathrm{~N}, 122 \mathrm{~W}$ & I \\
\hline 28 & $O C I$ & Oyster Condition Index & $1980\left(\downarrow^{*}\right)$ \\
\hline 29 & WCMACK & West Coast mackerel recruitment & $1976(\uparrow *)$ \\
\hline 30 & $W A \_C O$ & Washington coho catch & 1992( $\left.\downarrow^{*}\right)$ \\
\hline 31 & WA_PI & Washington pink catch & $1981\left(\downarrow^{*}\right)$ \\
\hline 32 & $O R_{-} C O$ & Oregon coho catch & $1992\left(\downarrow^{*}\right)$ \\
\hline
\end{tabular}

Note: The abbreviations for the data series are plotted in Fig. 5. ' $\downarrow$ ' and ' $\uparrow$ ' stand for decrease shift and increase shift, respectively. The test is conducted on the timescale of 10-year. The shift is confirmed if its significance level is over $90 \%$ ('*' for $95 \%$ ). 


\subsection{Potential ecological effect of the regime shift}

Physical environment abrupt change was proved to have resulted in regime shift in the biology field (Hare and Mantua, 2000). In regard to the JZB ecosystem, BEN showed a decreasing shift in 1978 on a decadal timescale $(p<0.1)$ (Fig. 6), which is consistent with A-PR decrease and A-SST increase. In the JZB, silicate, which comes from seasonal fluvial loads, is one of the most important limiting elements for diatom growth (Yang Dongfang et al., 2005, 2006). The river discharge varied along with precipitation. Clearly, the A-PR decrease has a significant potential impact on diatom cell abundance. A-SST increase may accelerate the photo- synthesis and metabolism processes in the meantime. The decrease of diatoms responding to A-SST increase suggests that the cold species may contribute to total phytoplankton biomass. Besides the 1978 shift, BEN shows two minor abrupt changes, negative shift in 1972 and positive shift again after 1996. The 1972 shift might be ascribed to SST increase in the early 1970s. There is no regional dramatic change corresponding to the 1996 shift. The only causative reason might be related to the great aquaculture disaster in 1995 when shellfish in the JZB suffered from the accidental mortality (Jiao Nianzhi, 2001). Shellfish mortality greatly released the predating pressure of diatom growth, possibly resulting in BEN increase.

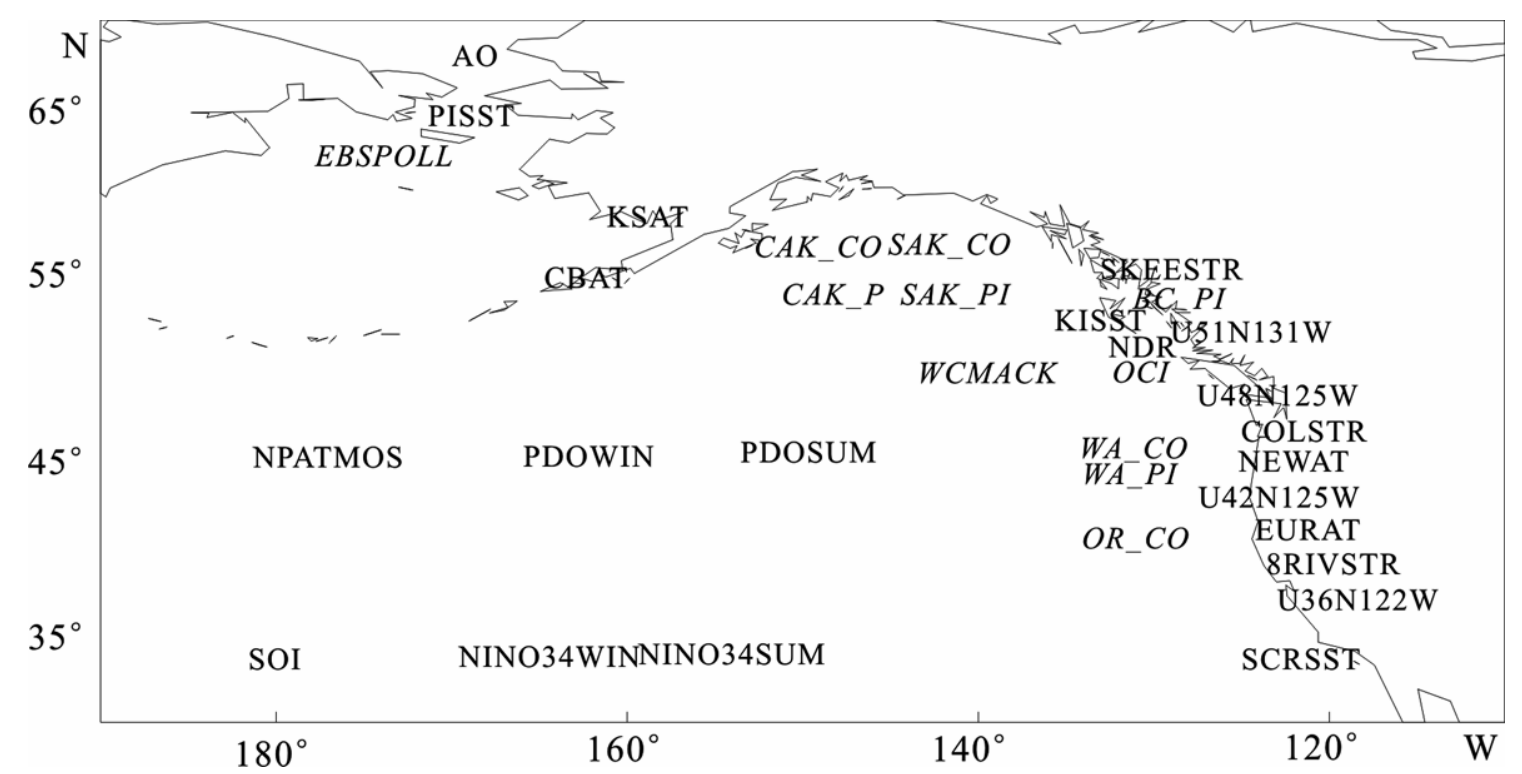

Fig. 5. The abbreviations for the physical and biological time series in the central and eastern parts of the North Pacific Ocean. They are geographically plotted in the places where the variables are measured or have influence.

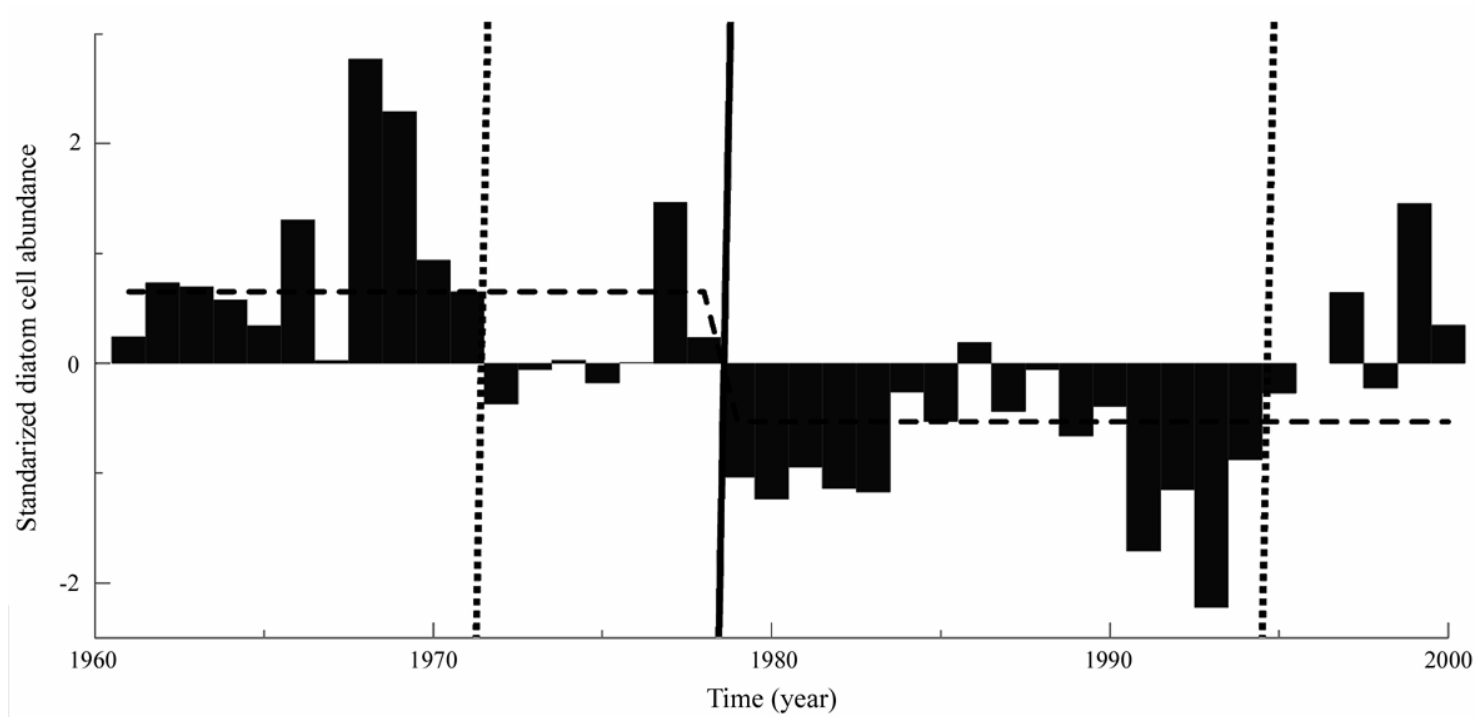

Fig. 6. The normalized benthic cell abundance during 1961-2000. The brown vertical solid line and two dashed lines indicate, respectively, the 1978 shift in the 10-yearr period and 1972 and 1995 shifts in the 5-year period. The black dashed line indicates the separation of two regimes by the notable 1978 shift. 


\section{Conclusions}

During the period of 1961-2000, the physical environment was characterized by significant variations. AT, SST and SSS showed positive trends, while PR showed a negative trend. Anomalies of the local environment accord with global climate change indices, i.e., SOI and AO. Power spectrum analysis and wavelet transform revealed that the variability for the physical environment has features of the interannual (about 2-3 years and 5-6 years) and decadal (about 10-11 years) periods with these different wave components being dominated in the fluctuations in different stages.

Abrupt changes on multiple timescales play an essential role in the physical environment temporal variations. Most of these significant shifts, such as the 1976-1978 and 1988-1989 shifts are consistent with climate regime shift in the Northern Hemisphere induced by atmosphere circulation variability. SST and PR regime shifts around 1978 have a notable impact on the BEN abrupt decrease in the decadal period. The BEN minor shift in 1972 is due to the SST shift in the early 1970s. The abundance showed a positive trend again after 1995, possibly because of shellfish mortality in 1995. This study provides evidence suggesting that the regime shift due to global change as well as its ecologic impact is significant not only in the central and eastern parts of the North Pacific region, but also in the marginal seas' coastal regions of the West Pacific region which is highly influenced by local human activities.

Acknowledgements This study was financially supported jointly by the National Natural Science Foundation of China (Grant No. 40036010) and the Special Fund for Public Welfare Industry (Oceanography) (Grant No. 200805011).

\section{References}

Chu Paoshin and Zhao Xin (2003) Bayesian change-point analysis of tropical cyclone activity: The central north pacific case [J]. Journal of Climate. 17, 4893-4901.

Chylek P., Folland C.K., Lesins G., Dubey M.K., and Wang M. (2009) Arctic air temperature change amplification and the Atlantic Multidecadal Oscillation [J]. Geophysical Research Letters. 36, 14.

Daubechies I. (1992) Ten Lectures on Wavelets, CBMS-NSF Series on Applied Mathematics [M]. SIAM, Philadelphia.

Denman K.L. and Pena M.A. (2002) The response of two coupled one-dimensional mixed layer/planktonic ecosystem models to climate change in the NE subarctic Pacific Ocean [J]. Deep Sea Research Part
II: Topical Studies in Oceanography. 49, 5739-5757.

Fang Guohong, Wang Kai, Guo Fengyi, Wei Zexun, Fan Wenjing, Zhan Dongsheng, and Bi Jiasheng (2002) Long-term changes and interrelations of annual variations of the hydrographical and meteorological parameters of the Bohai Sea during recent 30 years [J]. Ocean et Limnologia Sinica. 33, 515-524 (in Chinese with English abstract).

Graham N.E. (1994) Decadal-scale climate variability in the 1970's and 1980's: Observations and model results [J]. Climate Dynamics. 10, 135-162.

Guo Yonglu, Ren Yiping, and Yang Hanbin (2005) A study on the growth characteristics of the clam ruditapes philippinarum in Jiaozhou Bay [J]. Periodical of Ocean University of China. 35, 779-784 (in Chinese with English abstract).

Hare S.R. and Mantua N.J. (2000) Empirical evidence for North Pacific regime shifts in 1977 and 1989 [J]. Progress in Oceanography. 47, $103-145$.

Jiao Nianzhi (2001) Ecological Processes and Sustainable Development of Typical Coastal Water Ecosystems in China [M]. Science Press, Beijing (in Chinese).

Lin Chuanlan, Ning Xiuren, Su Jilan, Lin Yian., and Xu Bingrong (2005) Environmental changes and the responses of the ecosystems of the Yellow Sea during 1976-2000 [J]. Journal of Marine System. 55, 223-234.

Lin Chuanlan, Su Jilan, Xu Bingrong, and Tang Qisheng (2001) Long-term variations of temperature and salinity of the Bohai Sea and their influence on its ecosystem [J]. Progress in Oceanography. 49, 7-19.

Liu Sumei, Zhu Bingde, Zhang Jing, Wu Ying, Liu Guangshan, Deng Bing, Zhao Meixun, Liu Guanqun, Du Jinzhou, Ren Jingling, and Zhang Guiling (2010) Environmental change in Jiaozhou Bay recorded by nutrient components in sediments [J]. Marine Pollution Bulletin. 60, 1591-1599.

Liu Dongyan (2004) Community Structure Succession study of Phytoplankton and Sediment Diatom in Jiaozhou Bay [D]. Ocean University of China (in Chinese with English abstract).

Lu Jiwu, Wu Yaoquan, and Zhang Fazhong (2001) Fishery resource analysis and ecological fishery management. In Ecological Processes and Sustainable Development of Typical Coastal Water Ecosystems in China (ed. Jiao Niaozhi) [M]. pp.284-312. Science Press, Beijing (in Chinese).

Mann M.E. and Park J. (1996) Joint spatiotemporal modes of surface temperature and sea level pressure variability in the northern hemisphere during the last century [J]. Journal of Climate. 9, 2137-2162.

Mantua N. (2004) Methods for detecting regimeshifts in large marine ecosystems: a review with approaches applied to North Pacific data [J]. Progress in Oceanography. 60, 165-182.

McGowan J.A., Bogradb S.J., Lynnc R.J., and Millera A.J. (2003) The biological response to the 1977 regime shift in the California Current [J]. Deep Sea Research Part II: Topical Studies in Oceanography. 50, 2567-2582.

Miettinen A., Divine D., Koç N., Godtliebsen F., and Hall I.R. (2012) Multicentennial variability of the sea surface temperature gradient across the subpolar North Atlantic over the last $2.8 \mathrm{ka}[\mathrm{J}]$. Journal of Climate. 25, 4205-4219.

Minobe S. (1997) A 50-70 year climatic oscillation over the North Pacific and North America [J]. Geophysical Research Letters. 24, 683-686. 
Savelieva N.I., Semiletov I.P., Vasilevskaya L.N., and Pugach S.P. (2000) A climate shift in seasonal values of meteorological and hydrological parameters for Northeastern Asia [J]. Progress in Oceanography. 47, 279-297.

Thompson D.W.J. and Wallace J.M. (1998) The Arctic oscillation signature in winter geopotential hight and temperature fields [J]. Geophysical Research Letters. 25, 1297-1300

Torrence C. and Compo G.P. (1998) A practical guide to wavelet analysis [J]. Bulletin of the American Meteorological Society. 79, 61-78.

Yang Dongfang, Gao Zhenhui, Wang Peigang, Sun Peiyan, and Liu Shuang
(2005) Silicon limitation on primary production and its destiny in Jiaozhou Bay, China. V. Silicon deficit proces [J]. Chinese Journal of Oceanology and Limnology. 23, 169-175.

Yang Dongfang, Gao Zhenhui, Sun Peiyan, Zhao Sheng, and Zhang Youchi (2006) Silicon limitation on primary production and its destiny in Jiaozhou Bay, China. VI. The ecological variation process of the phytoplankton [J]. Chinese Journal of Oceanology and Limnology. 24, 186-203.

Zhang Yuan, Wallace J.M., and Battisti D.S. (1997) ENSO-like interdecadal variability: 1900-1993 [J]. Journal of Climate. 10, 1004-1020. 